\title{
Hematoperitoneum after small-bowel spiral enteroscopy
}

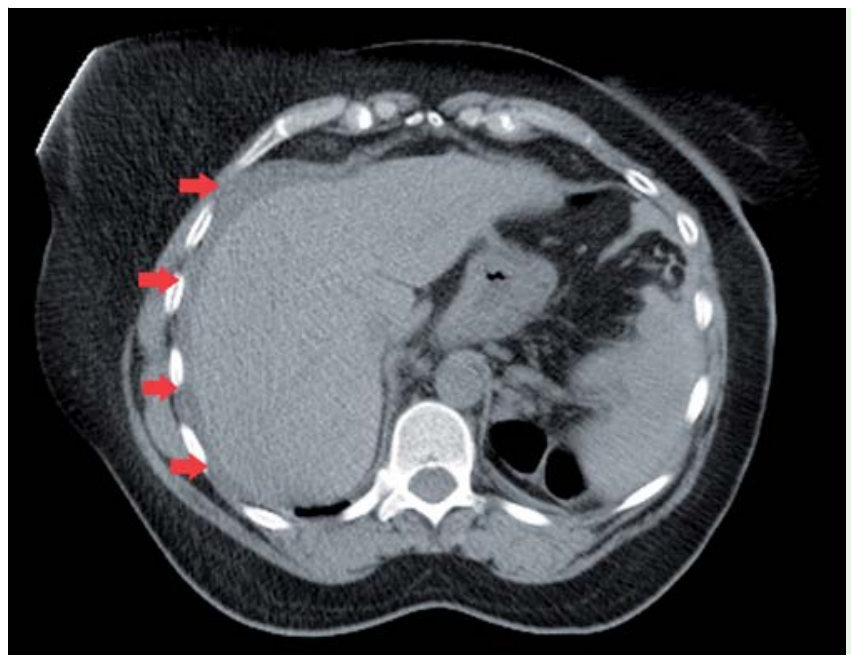

Fig. 1 Axial computed tomography (CT) of abdomen and pelvis in a 62-year-old woman with a 3-day history of melena. Hyperdense fluid adjacent to the liver (red arrows) can be seen. There is no free air.

Advances in endoscopy including spiral enteroscopy [1] have transformed the management of small-bowel diseases, and published data have demonstrated this to be a safe procedure [2-8]. We report the first case, related to spiral enteroscopy, of hematoperitoneum in a 62-year-old woman.

Our patient presented to the emergency room with a 3-day history of melena. Her past medical history was significant for obscure gastrointestinal bleeding, and left nephrectomy. Given the previous extensive negative workup for obscure gastrointestinal bleeding, spiral enteroscopy was carried out. This showed nonbleeding angiectasias in the proximal and mid-jejunum, which were treated with argon plasma coagulation. Within a few hours the patient developed severe abdominal pain that radiated to her shoulders, and was noted to be tachycardic and hypotensive. Abdominal and pelvic computed tomography (CT) showed fluid in the abdomen consistent with hematoperitoneum ( Fig. 1). The patient was transferred to the intensive care unit and managed conservatively with fluids and blood transfusion. She improved clinically and was discharged in a stable condition.

As with many patients undergoing deep enteroscopy, this group has had previous intra-abdominal procedures, which was also the case in our patient, who had undergone left nephrectomy. Deep enteroscopy can stretch or apply torque to adhesions and the mesentery with the potential of disruption of blood vessels. This puts any patient undergoing deep enteroscopy at risk from the inadvertent tearing of adhesions. The fact that thousands of these procedures have been done without major complications, including hematoperitoneum [4-8], suggests that fortunately this is very rare. Akerman et al. reported the rate of severe adverse events with spiral enteroscopy to be only $0.3 \%$ [9]. It can be concluded from the published literature that deep enteroscopy is a safe and effective technology with a low rate of major complications, however, clinicians should remain aware that these events can occur and are not immediately obvious.

\section{Endoscopy_UCTN_Code_CPL_1AI_2AD}

\section{Competing interests: None}

\section{B. Gondal ${ }^{1}$, J. Charpentier' ${ }^{2}$, D. Cave ${ }^{2}$}

${ }^{1}$ Department of Medicine, UMass Memorial Medical Center, Worcester, Massachusetts, United States of America

2 Department of Gastroenterology, UMass Memorial Medical Center, Worcester, Massachusetts, United States of America

\section{References}

1 Akerman PA, Cantero D. Spiral enteroscopy and push enteroscopy. Gastrointest Endosc Clin N Am 2009; 19: 357-369

2 Satish N, Jill G, Peter VD et al. Retrograde spiral enteroscopy: feasibility, success, and safety in a series of 22 patients. Gastrointest Endosc 2011; 3: 699-702

3 Mouen AK, Anne Marie L, Kerry B et al. A comparative evaluation of single-balloon enteroscopy and spiral enteroscopy for patients with mid-gut disorders. Gastrointest Endosc 2010; 72: $766-772$

4 Judah JR, Draganov PV, Lam Y et al. Spiral enteroscopy is safe and effective for an elderly United States population of patients with numerous comorbidities. Clin Gastroenterol Hepatol 2010; 8: 572 - 576

5 Morgan DR, Upchurch BR, Draganov PV et al. Spiral enteroscopy: prospective multicenter US trial in patients with small bowel disorders. Gastrointest Endosc 2009; 69: AB127-128

6 Esmail S, Odstrcil EA, Mallat D et al. A single center retrospective review of spiral enteroscopy. Gastrointest Endosc 2009; 69: AB197

7 Schembre $D$, Ross A. Yield of double balloon versus spiral enteroscopy for obscure gastrointestinal bleeding. Gastrointest Endosc 2009; 69: AB193

8 Buscaglia JM, Dunbar KB, Okolo PI et al. The spiral enteroscopy training initiative: results of a prospective study evaluating the Discovery SB overtube device during small bowel enteroscopy (with video). Endoscopy 2009; 41: 194-199

9 Akerman PA, Cantero D. Complications of spiral enteroscopy in the first 2950 patients. Paper presented at: Gastro 2009, November 21-25, London, UK

\section{Bibliography}

Dol http://dx.doi.org/

10.1055/s-0033-1344585

Endoscopy 2013; 45: E337

(c) Georg Thieme Verlag KG

Stuttgart - New York

ISSN 0013-726X

\section{Corresponding author \\ Dr B. Gondal}

Department of Internal Medicine

University of Massachusetts Memorial Medical School

Worcester

Massachusetts 01655

USA

Fax: +508-856-3981

Bilal.Gondal@umassmemorial.org

bilalgz@gmail.com 